\title{
Disasters in Germany and France: An Analysis of the Emergency Events Database From a Pediatric Perspective
}

\author{
Markus Ries, MD, PhD; Matthias Zielonka, MD; Noah Ries; Thomas Breil, MD; \\ Sven Garbade, PhD; Konstantin Mechler, MD
}

\section{ABSTRACT}

Objective: The objective of this study was to conduct comprehensive analyses of disaster patterns for Germany and France from a pediatric perspective.

Methods: An analysis of the Emergency Events Database (EM-DAT), epidemiological database with standard methods of descriptive and comparative statistics respecting the strengthening the reporting of observational studies in epidemiology (STROBE) criteria, was performed.

Results: Between 2006 and 2016, there were 41 and 42 disasters in Germany and France claiming 259 and 4973 lives, respectively. Ages of afflicted individuals were not specified in EM-DAT. In Germany, most events were storms (37\%), extreme temperatures (17\%), floods (17\%), and transport accidents (17\%). In France, most events were storms (45\%), extreme temperatures (17\%), floods (19\%), and transport accidents (14\%). In Germany, most lives (96) were lost in transport accidents. In France, most casualties were due to the heat waves of 2006 and 2015 (1388 and 3275). Reported event types in Germany and France were similar, but heat waves struck France more significantly than Germany.

Conclusions: Pediatric data are not explicitly captured in EM-DAT, but reported disaster patterns suggest that exposures to heat and cold, storms, trauma, chemicals, water, and infectious agents are possible mechanisms of injury. Age-stratified disaster data are needed to enable a timely, transparent, coordinated, and sustained data-driven approach to pediatric disaster resilience.

Key Words: disasters, disaster medicine, education, public health professional, emergency preparedness, epidemiologic methods

$\mathrm{T}$ oday's societies face many types of civilian mass casualty disasters, including natural and man-made catastrophic events that pose a particular threat to children. ${ }^{1-6}$ Yet, disasters are not a new phenomenon, and their existence and/or common perception can be dated back to history's beginnings itself (eg, Mount Tai earthquake, biblical plagues). ${ }^{7}$ The exact number of children worldwide affected by conflicts, war, and disaster is unknown. Yet, the United Nations International Children's Emergency Fund (UNICEF) Machel study investigated the effects of armed conflicts on children from approximately 100 countries over a period of 10 years with an unprecedented scope. The results showed that nearly more than one billion children live in conflict areas - almost one sixth of the total world population, 300 million of them younger than 5 years. ${ }^{8}$ Precise longitudinal pediatric data on patterns of disasters are not available. A comprehensive understanding of disaster patterns would help identify the need of children in specific disasters and strengthen resilience against threats. A comparison of disaster patterns in two neighboring industrialized countries, in this case, Germany and France, which account for almost one third of the overall population in the European Union, helps identify commonly faced issues and differences and may help align bilateral disaster mitigating strategies or bundling of resources. Pediatric perspectives of disaster medicine are important because children per se are particularly vulnerable in catastrophic events due to their (1) physiology and (2) dependency on caretakers. ${ }^{9}$ Stressful life events such as exposure to traumatizing and life-threatening situations, which are probably to be encountered during a disaster, may result in mental disorders such as posttraumatic stress disorder (PTSD) ${ }^{10}$ with significant financial implications, because, in general, costs of mental illnesses in children and adolescents have been estimated to be 10 -fold higher than those with an adult onset. ${ }^{11,12} \mathrm{~A}$ thorough understanding of disaster risk patterns and opportunities for pediatric disaster resilience is of great relevance because children represent almost one-fifth of the population in Germany and France. Currently, 13134352 individuals in Germany are less than 18 years old, which 
corresponds to $16 \%$ of the overall population. ${ }^{13}$ Likewise, a disaster would potentially affect 14183189 individuals under 18 years of age in France (ie, 22\% of the overall population). ${ }^{14}$

We therefore directed our efforts in assessing and analyzing disaster patterns in Germany and France. The primary goal of this analysis was to characterize disasters and their impact occurring over the last 10 years, in general. The secondary goal was an exploration of the overall disasters in the two countries between 1900 and 2016, and the description of the 10 most significant disaster events in both countries registered in the Emergency Events Database (EM-DAT).

\section{METHODS}

\section{Availability of Data on Disasters - the EM-DAT}

Data on natural and technological disasters from 1900 to present are hosted in the EM-DAT at the Centre for Research on the Epidemiology of Disasters at the School of Public Health of the Université catholique de Louvain located in Brussels, Belgium. ${ }^{15}$ Launched in 1988, this database is a major authoritative, easily accessible source of information for epidemiological disaster research disasters, captures more than 22000 worldwide mass disasters from data sources, including United Nations agencies, non-governmental organizations (NGOs), insurance companies, research institutes, and press agencies. ${ }^{15} \mathrm{~A}$ disaster is included in the database if one or more of the following criteria are fulfilled: (1) 10 or more people dead, (2) 100 or more people affected, (3) the declaration of a state of emergency, or (4) a call for international assistance. ${ }^{15}$ Data on terrorism and effects of warfare are not available in the EM-DAT. ${ }^{16}$

\section{Data Query}

The EM-DAT was accessed on December 26, 2016, through the Internet. ${ }^{15}$ Countries considered were Germany, Federal Republic of Germany, German Democratic Republic, and metropolitan France. Variables considered were "year," "group," "type," "subtype," and "total deaths." Years from the earliest available entries (1900) until December 26, 2016, were considered. Data were downloaded from the database in comma-separated values (CSV) format, which facilitates handling and processing of tabular data. Data were manually checked for plausibility. One entry was excluded because the dam collapse of Gleno (Italy) in 1923 was listed in the French dataset (Supplemental Figure 1). Missing data were not imputed. The analysis was conducted with GraphPad PRISM, a scientific graphing and statistics software (La Jolla, CA, USA).

\section{Statistics}

We analyzed (1) all reported events within the last 10 years for both Germany and France, (2) the overall pattern of natural and technological disasters in Germany and France between 1900 and 2016, and (3) the 10 most significant overall events in terms of causalities for both countries. Standard methods of descriptive statistics were applied. Strengthening the reporting of observational studies in epidemiology (STROBE) criteria, which represent a reporting guideline for observational studies, were respected by adhering to the STROBE checklist. ${ }^{17}$ The reported numbers of casualties during heat and cold waves were compared in a conservative approach with a two-tailed non-parametric Mann-Whitney test due to a small sample size. A P-value of less than .05 was considered statistically significant.

Figure 2 was computed with the ggmap ${ }^{18}$ extension for R environment and used Google Maps data.

\section{RESULTS}

\section{Disasters in Germany and France 2006-2016 as Registered in the EM-DAT ${ }^{15}$}

In the last decade, that is, between 2006 and 2016, there were 41 German and 42 French disaster events registered in the database (Supplemental Table 1 and Supplemental Table 2; Figure 1). Most events in Germany were storms (15/41, 37\%), followed by extreme temperatures $(7 / 41,17 \%)$, floods $(7 / 41,17 \%)$, and transport accidents $(7 / 41,17 \%)$. In France, most events reported from 2006-2016 were storms (19/42, 45\%), floods $(8 / 42,19 \%)$, extreme temperatures $(7 / 42,17 \%)$, and transport accidents (6/42, 14\%). In Germany, 259 lives were lost overall during disasters in the last decade. Transport accidents claimed most lives (96). In France, 4973 lives were lost overall in the last decade, most of them in the heat waves of 2015 and 2006 with 3275 and 1388 casualties, respectively.

\section{Disasters in Germany and France Between 1900 and 2016 and Most Significant Events as Registered in the EM-DAT ${ }^{15}$}

\section{Germany}

Overall, between 1900 and 2016, 168 natural or technological disasters affecting Germany leading to a total death toll of 13540 persons were registered in the database (Tables 1 and 2; Figure 2, Supplemental Figure 2A and Supplemental Figure 2B). Most single events were storms, transport accidents, and floods. Most lost lives were lost due to extreme temperature, followed by industrial accidents and transport accidents.

An overview of the 10 major single disasters affecting Germany is provided in Supplemental Table 3. The three events with the highest death toll were a heat wave in 2003, a mining accident in 1946, and an explosion of a chemical factory in 1921.

\section{France}

In the same period, 1900-2016, 241 natural or technological disasters were registered in France having claimed 31150 lives (see Tables 1 and 2; Figure 2, Supplemental Figure 3A and Supplemental Figure 3B). Most single events were storms, transport accidents, and floods. The two disaster types with 
Number and Distribution of Disasters Affecting Germany and France Between 1900 and 2016, as Reported in the EM-DAT

\begin{tabular}{|c|c|c|c|c|c|c|}
\hline Disaster Type & $\begin{array}{l}\text { Occurrence in Both } \\
\text { Countries }(\mathrm{N})\end{array}$ & $\begin{array}{l}\text { Percentage } \\
(\%)\end{array}$ & $\begin{array}{l}\text { Occurrence in } \\
\text { Germany (N) }\end{array}$ & $\begin{array}{l}\text { Percentage } \\
(\%)\end{array}$ & $\begin{array}{l}\text { Occurrence in } \\
\text { France }(\mathrm{N})\end{array}$ & $\begin{array}{c}\text { Percentage } \\
(\%)\end{array}$ \\
\hline Storm & 111 & 27 & 53 & 32 & 58 & 24 \\
\hline Transport accident & 101 & 25 & 48 & 29 & 53 & 22 \\
\hline Flood & 69 & 17 & 23 & 14 & 46 & 19 \\
\hline Industrial accident & 33 & 8 & 19 & 11 & 14 & 6 \\
\hline Miscellaneous accident & 29 & 7 & 7 & 4 & 22 & 9 \\
\hline Extreme temperature & 26 & 6 & 11 & 7 & 15 & 6 \\
\hline Wildfire & 13 & 3 & 1 & 1 & 12 & 5 \\
\hline Landslide & 11 & 3 & 1 & 1 & 10 & 4 \\
\hline Earthquake & 5 & 1 & 3 & 2 & 2 & 1 \\
\hline Epidemic & 4 & 1 & 2 & 1 & 2 & 1 \\
\hline Mass movement & 3 & 1 & 0 & 0 & 3 & 1 \\
\hline Drought & 4 & 1 & 0 & 0 & 4 & 2 \\
\hline Total & 409 & 100 & 168 & 100 & 241 & 100 \\
\hline
\end{tabular}

\section{FIGURE 1}

Number of Reported Disaster Main Types and Casualty Events by Country Between 2006 and 2016. DEU= Germany; FRA = France; $\Theta=$ number of casualties. ${ }^{20}$

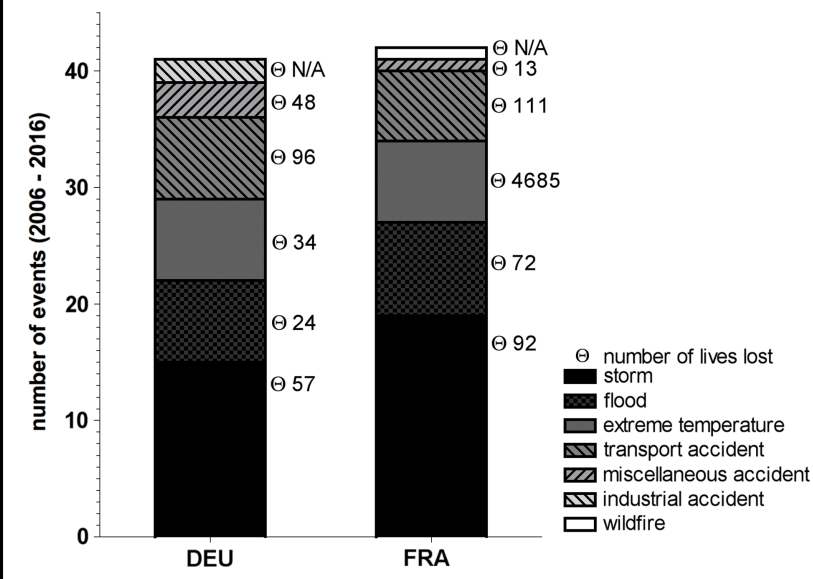

the highest number of casualties were extreme temperature and transport accidents. The three single disaster events with the highest death toll in France since 1900 were heat waves in 2003, 2015, and 2016 (Supplemental Table 4).

\section{Extreme Temperatures - Heat Versus Cold Waves}

Because extreme temperatures were the disaster type with the highest reported numbers of casualties reported in the EM-DAT, we conducted a subgroup analysis to compare human susceptibility against high versus low temperatures. Between 1900 and 2016, there were two heat waves reported in the EM-DAT for Germany and four reported for France. Likewise, there were 9 cold waves in Germany and 11 reported in France. In both countries, more lives were reportedly lost during heat waves compared with cold waves/severe winter (33 515 persons vs 137 persons, $P=.0273$, Mann-Whitney test, 23 events with available data).

\section{DISCUSSION}

\section{Disasters in Germany and France, 2006-2016}

The distribution patterns for the types of most reported events (storms, extreme temperatures, floods, transport accidents) indicated a similar risk pattern for injuries. Casualties of 259 and 4973 were reported for disasters in Germany and France, respectively. Whereas in Germany most lives (96) were lost in transport accidents within the last decade, in France, most deaths were due to the heat waves of 2006 and 2015 (1388 and 3275 casualties, respectively), which indicate that heat waves struck France more significantly than Germany during that time.

\section{Disasters in Germany and France Between 1900 and 2016 and Most Significant Events as Registered in the EM-DAT}

We explored the overall pattern of events for Germany and France available in the database, which covered the years 1900 to 2016. The EM-DAT reports that 409 natural or technological disasters affected Germany and France, leading to the loss of 44690 lives. Most single events in both countries were storms, transport accidents, and floods. Extreme temperatures, industrial, and transport accidents claimed most lives. The three single events with the highest death toll in Germany were the heat wave in 2003 (9355 casualties), the explosion of a chemical factory in 1921 (600 casualties), and a mining accident in 1946 (439 casualties), and in France the heat waves of 2003, 2015, and 2016 (19 490, 3275, and 1388 casualties, respectively). Otherwise, the distribution of events and casualties between Germany and France appeared to exhibit a 
Germany and France: Geographical Distribution of the Major Technological Disasters (Supplemental Table 3 and Supplemental Table 4) Between 1900 and 2016 Registered in the EM-DAT. $\bullet=$ miscellaneous accident; $\Delta=$ transport accident; $\mathbf{a}=$ industrial accident.

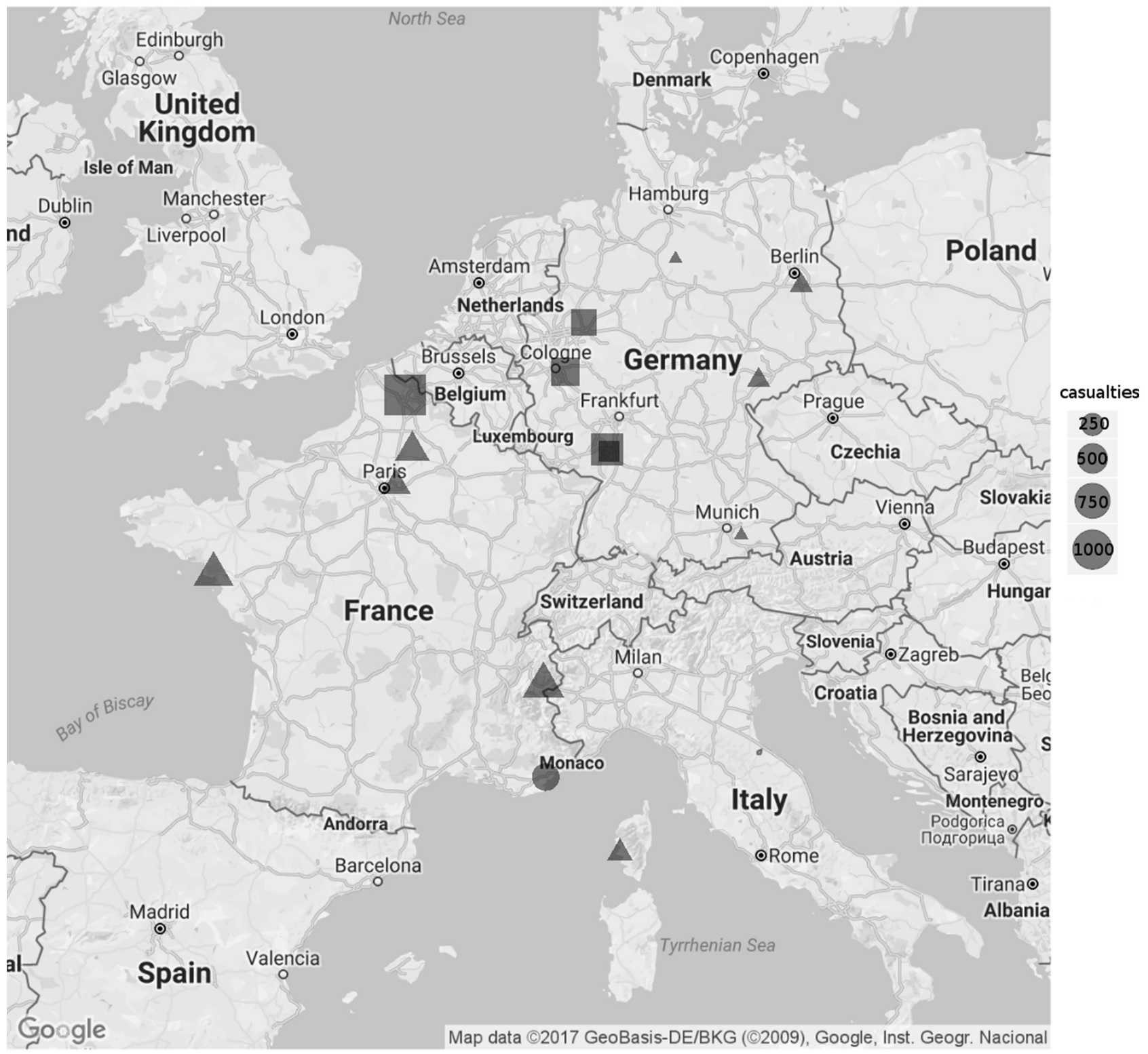

similar pattern. A major limitation of this long time EM-DAT analysis is the finding that the historical data entries may not be complete. Specifically, the 1918-1919 influenza pandemic, which caused an excess mortality of 237509 in France between August 1918 and April 1919, and 426574 between March 1918 and January 1919 in Germany, is not captured in the EM-DAT. ${ }^{19}$ Furthermore, there is no data entry for the other three major influenza pandemic waves in France and Germany of 1957-1958, 1968-1970, and 2009, which caused the loss of 29, 100, 46 900, and 350 lives alone in Germany. ${ }^{21}$ In addition, as illustrated in Supplemental Figure 2 and Supplemental Figure 3, there are fewer events reported before 1988 compared with after 1988, the launch date of the database. Issues with historical data are common in registry databases, including registries for diseases; missing data, recall, and ascertainment bias therefore limit generalizability. ${ }^{22,23}$ There are, however, situations where retrospectively collected data allow helpful insight into issues that cannot be quickly investigated otherwise, especially when prospective studies are not feasible or would require a long time to collect 


\section{TABLE 2}

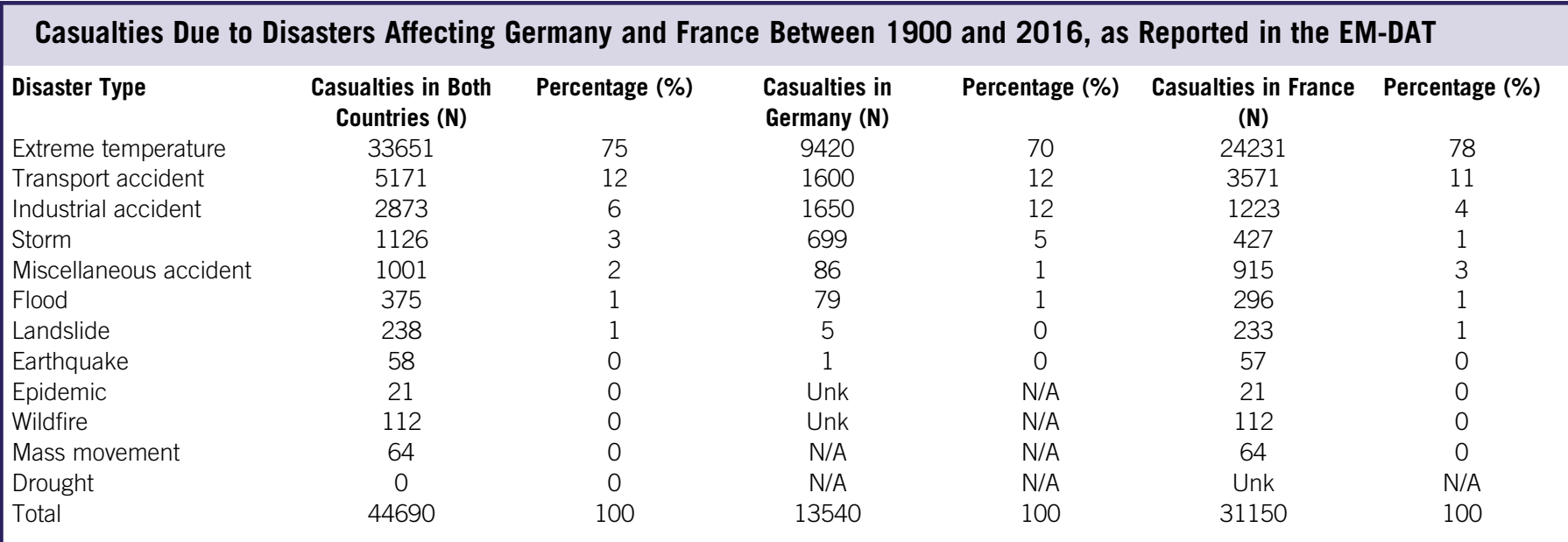

\section{TABLE 3}

\section{Selected Mechanisms of Injuries in Natural and Technological Disasters and Potential Preventive Measures}

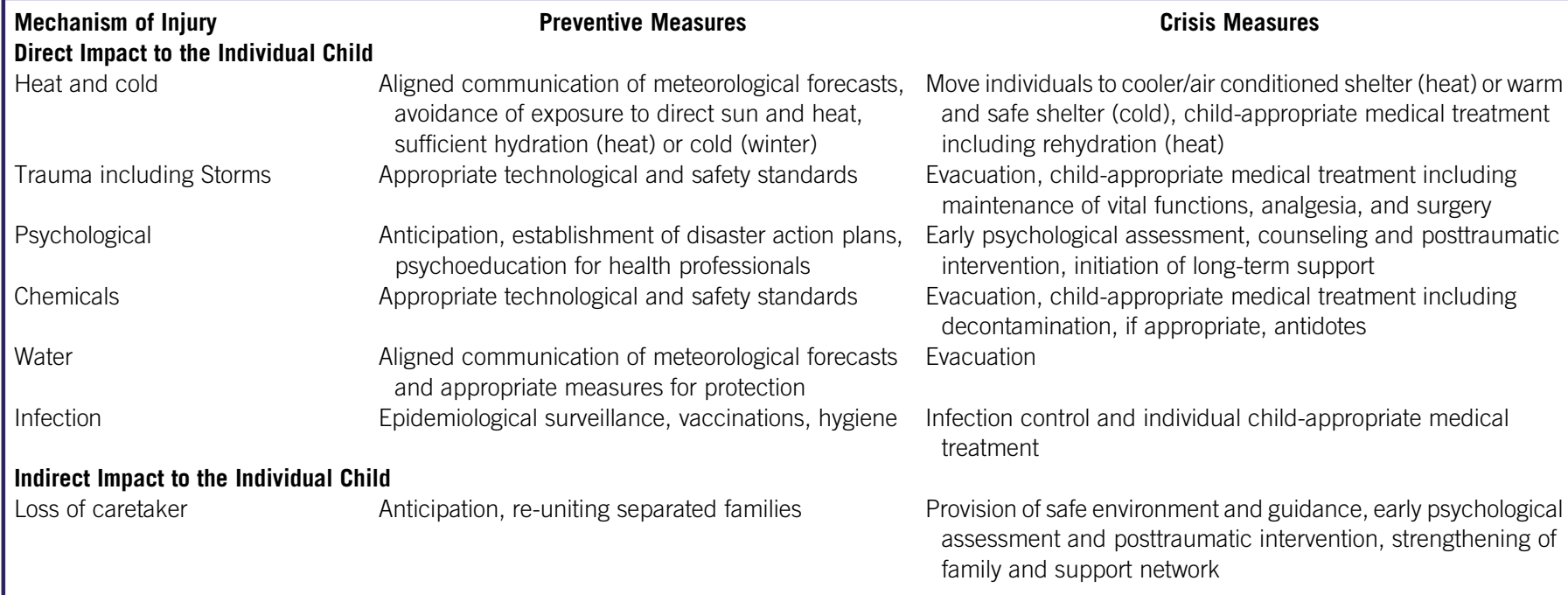

sufficient data. ${ }^{24,25}$ Therefore, the supposedly incomplete historical data in this analysis may serve as a helpful orientation but should be interpreted with caution.

\section{Pediatric Data - the Blind Spot}

Information in the EM-DAT was not stratified for pediatric data. Therefore, the pediatric interpretation hereafter is deducted, rather than being based on age stratified subgroup analyses, which would have been the ideal situation and allow data-driven decision making in pediatric disaster epidemiology. The present data of disaster patterns in the EM-DAT suggest that heat and cold (extreme temperatures) and trauma (accidents, explosion, storms, moving elements) may represent an important risk to children in disasters in both countries.
In addition, exposure to chemicals (explosions, industrial accidents), water (flood), and infectious agents (epidemics) are potential mechanisms of disaster-related injuries (Table 3). Although not specifically captured in the database, diseases due to heat waves would include heat stroke, heat exhaustion, and dehydration. ${ }^{26,27}$ Substantial psychological burden is to be anticipated. Exposure to stressful life events may lead to PTSD following a complex etiology that is mediated by many factors, for example: (epi-) genetic, familiar, trauma characteristics, subjective, pre- and post-trauma variables. ${ }^{28,29}$ Moreover, there is evidence that depressive disorders are more common resulting mental disorders after natural disasters. ${ }^{30}$ Yet, scientific evaluation of various disasters in the last decades has shown that the majority of exposed children did not develop PTSD or disaster-related mental disorders. ${ }^{31-34}$ This can be 
attributed to the construct of resilience, which is widely researched but still poorly understood. ${ }^{35-39}$ We favor an ageappropriate, transparent communication with children about risks and measures of prevention and mitigation. This should occur in a confident setting (eg, school) and whenever possible with inclusion of trusted persons, for example, parents and teacher. Playful educational online tools also may be helpful. ${ }^{40}$

Rothstein reviewed strategies of pediatric care in disasters and proposed top 10 priorities in the emergency phase of a catastrophe (ie, initial assessment, measles immunization, water and sanitation, food and nutrition planning, shelter and site planning, health care in emergency phase, control of communicable diseases and epidemics, public health surveillance, human resources and training, and coordination). ${ }^{41}$ Likewise, one should keep in mind that the seven sins of humanitarian medicine (ie, leaving a mess behind, failing to match technology to local needs, failure of NGOs to cooperate with each other, failing to have a follow-up plan, allowing politics or training to trump service, going where we are not wanted or needed, and doing the right thing for the wrong reason) are to be avoided. ${ }^{41,42}$ This implies that the preventive and interventional approach toward pediatric care in disaster situations should be timely, transparent, coordinated and sustained, and ideally be data-driven. From an epidemiological and logistic perspective (eg, type of food needed, immunization, dehydration risk, drug supply including galenic formulation, surgery and anesthesia equipment, and need of infant transportation equipment), it would be important to know which age groups are specifically affected.

Challenges in taking care of children in disaster situations occur on four main levels. First, unaccompanied children are vulnerable. This is of relevance because geographical dynamics that change on a circadian pattern - children attending daycare or school and parents going to work - may lead to a separation of families in case of an unexpected event. ${ }^{43}$ Lessons learned from the 2010 earthquake in Haiti were not to separate families in case of a disaster and to quickly establish communication channels between family members. ${ }^{44}$ Second, the physiology of the pediatric organism changes with age from neonates at adolescents. ${ }^{45}$ This leads to particular vulnerabilities, such as the increased susceptibility to cold and the risk of rapid dehydration in neonates, infants, or toddlers. Children are more vulnerable to chemical contamination in the air, because their respiratory frequency is higher than in adults. ${ }^{46}$ Children may be less resilient to seasonal temperature changes and living conditions due to loss of shelter after evacuation, as experienced in Japan in 2011. ${ }^{47}$ Furthermore, psychological or pharmacological interventions must be age appropriate; in addition, pediatric pharmacology deserves particular consideration for the availability of medical supplies and stockpiling. ${ }^{9,48,49}$ Third, disease-inherent dynamics can be different in children compared with adults, and chronic medical problems may exacerbate in a crisis situation. ${ }^{24}$ Therefore, the availability of personnel with training in pediatrics is of advantage. ${ }^{48,50,51}$ Fourth, pediatric surgical expertise is essential for children in conflict and disaster situations. ${ }^{52}$ Orthopedic injuries like fractures or amputations, neurosurgical lesions and burns, merit special pediatric knowledge. Besides, pediatric perioperative care and safe anesthesia are required for survival and successful outcome.

Census data may be of value in identifying populations-at-risk, as recently demonstrated in Japan after the Great Eastern Japan earthquake on March 11, 2011; although, as in many disaster analyses, pediatric aspects were not specifically considered. ${ }^{53} \mathrm{~A}$ Web-based centralized tracking system with the goal to reunite families as soon as possible was suggested as a lesson from the events in Japan. ${ }^{54}$ An analysis of impact and longterm health effects of the disasters at Seveso, Three Mile Island, Bhopal, Chernobyl, the World Trade Center, and Fukushima concluded that health surveillance and treatment programs for affected responders and residents, including children, are important. Furthermore, detailed emergency preparedness plans are critical to mitigate future threats. ${ }^{55}$ In 2010, Starmer et al. emphasized the need to mitigate possible disasters by community and societal preparation by inclusion of families and children in the preparation to respond and through access to support services. ${ }^{56,57}$ Ideally, pediatricians and families should actively be involved in governmental advice for disaster planning. ${ }^{56}$

Last, but not least, appropriate education of pediatric health care professionals is crucial for disaster resilience. Although education in pediatric disaster medicine is usually not a core component of medical school curricula or specialty training in pediatric residency programs, closing knowledge and competency gaps are important. ${ }^{58-61}$ In the United States, the National Center for Disaster Medicine and Public Health put forward an initiative to develop such a training program. ${ }^{62}$ An update on the current state of this work in progress was published by Siegel et al. in $2014 .^{63}$

\section{Limitations and Directions for Future Research}

This analysis is based on events registered in the EM-DAT because (1) this database is a major source of epidemiological information on disasters and (2) the database is easily accessible. The present analysis relies on the accuracy of the reported data. Detailed original source data verification was logistically not feasible and was therefore not undertaken. There are other databases available, such as NatCatSERVICE (Natural catastrophe know-how for risk management and research, owned by the insurance company Munich Re, Germany), Sigma (catastrophe database, owned by the insurance company Swiss Re, Switzerland), GLIDE (Global Identifier number, Asian Disaster Reduction Center, Japan), DesInventar (Sistema de Inventario de Desastres, Corporación OSSO, Columbia, and La Red de Estudios Sociales en Prevención de Desastres en América Latina, Panama), and SHELDUS (Spatial Hazard Events and Losses 
Databases for the United States, Hazards and Vulnerability Research Institute, University of South Carolina, USA), but these are either less comprehensive or do not cover both countries of interest in this report. ${ }^{16}$ As outlined previously, historical data in the database may be less accurate than the prospectively collected information due to ascertainment bias, illustrated by the finding that the 1918-1919, 1957-1958, 1968-1970, and 2009 influenza pandemic wavers with their substantial mortality were not covered at the time of data query. The impact of armed conflicts is not taken into account in the EM-DAT. We speculate that this may introduce a bias because the outcome of disasters in wartime may be worse. It is possible that resource constraints or decreased societal resilience in wartime may lead to higher infant mortality, hunger, and malnutrition in children. The major issue, from a pediatric perspective, is the fact that mortality data reported in the EMDAT were not separately available for adults and children, which might introduce an age bias into this analysis if a certain age segment of the overall population has either a particular vulnerability or a specific resilience to certain injuries. Moreover, capturing pediatric information in the EM-DAT would allow better data-driven decision making for children in catastrophic situations in the future.

\section{CONCLUSIONS}

Although explicit pediatric data are not captured in the EMDAT, the reported disaster patterns suggest that exposures to heat and cold, storms, trauma, chemicals, water, and infectious agents are possible mechanisms of injury to children in catastrophes in Germany and France. Age-stratified disaster data are needed to enable a timely, transparent, coordinated, and sustained data-driven approach to pediatric disaster resilience.

\section{About the Authors}

Pediatric Neurology and Metabolic Medicine, Center for Pediatric and Adolescent Medicine Heidelberg University Hospital, Heidelberg, Germany (Drs Ries, Zielonka, Garbade); Kurfürst-Friedrich Secondary School, Heidelberg, Germany (Mr Ries, N.); Pediatric Gastroenterology, Center for Pediatric and Adolescent Medicine, Heidelberg University Hospital, Heidelberg, Germany (Dr Breil); Department of Child and Adolescent Psychiatry and Psychotherapy, Central Institute of Mental Health, Medical Faculty Mannheim, University of Heidelberg, Mannheim, Germany (Dr Mechler)

Correspondence and reprint requests to Markus Ries, Pediatric Neurology and Metabolic Medicine, Center for Pediatric and Adolescent Medicine, University Hospital Heidelberg, Im Neuenheimer Feld 430, D-69120 Heidelberg, Germany (e-mail:markus.ries@uni-heidelberg.de).

\section{Conflict of Interest Statement}

The authors have no conflicts of interest to declare.

\section{Supplementary material}

To view supplementary material for this article, please visit https://doi.org/10.1017/dmp.2019.24

\section{REFERENCES}

1. Barthel ER, Pierce JR, Goodhue CJ, et al. Can a pediatric trauma center improve the response to a mass casualty incident? J Trauma Acute Care Surg. 2012;73(4):885-889.

2. Goodhue CJ, Burke RV, Ferrer RR, et al. Willingness to respond in a disaster: a pediatric nurse practitioner national survey. J Pediatr Health Care. 2012;26(4):e7-20.

3. Gold JI, Montano Z, Shields S, et al. Pediatric disaster preparedness in the medical setting: integrating mental health. Am J Disaster Med. 2009;4(3):137-146.

4. Shirm S, Liggin R, Dick R, Graham J. Prehospital preparedness for pediatric mass-casualty events. Pediatrics. 2007;120(4):e756-761.

5. Burke RV, Kim TY, Bachman SL, et al. Using mixed methods to assess pediatric disaster preparedness in the hospital setting. Prehosp Disaster Med. 2014;29(6):569-575.

6. Berman S. Pediatric education in disasters manual. 2009. https://www.aap. org/en-us/advocacy-and-policy/aap-health-initiatives/children-anddisasters/Documents/peds-full-eng_2012.pdf. Accessed March 14, 2017.

7. Isodorus Hispalensis. De natura rerum. 9th century. http://nbn-resolving. de/urn:nbn:de:bvb:22-dtl-0000025375. Accessed March 14, 2017.

8. UNICEF. Machel study 10-year strategic review. Children and conflict in a changing world. 2009. https:/www.unicef.org/publications/files/ Machel_Study_10_Year_Strategic_Review_EN_030909.pdf. Accessed May 3, 2017.

9. Markenson D. Have we forgotten about the needs of children? Disaster Med Public Health Prep. 2014;8(3):188-190.

10. Furr JM, Comer JS, Edmunds JM, Kendall PC. Disasters and youth: a metaanalytic examination of posttraumatic stress. J Consult Clin Psychol. 2010;78(6):765-780.

11. Lee FS, Heimer H, Giedd JN, et al. Mental health. Adolescent mental health- opportunity and obligation. Science. 2014;346(6209):547-549.

12. Suhrcke M, Pillas D, Selai C. Economic aspects of mental health in children and adolescents. 2007. http://www.euro.who.int/_data/assets/ pdf_file/0003/76485/Hbsc_Forum_2007_economic_aspects.pdf?ua=1. Accessed May 3, 2017.

13. Statistisches Bundesamt [German Federal Statistics Office]. Table 12111-0004. 2017. https://www-genesis.destatis.de/genesis/online/data; jsessionid=0AC66E61553BE587F83F8CB6D4AF929D.tomcat_GO_2_1? operation $=$ abruftabelleAbrufen \&selectionname $=12111-0004 \&$ level index $=0$ \&levelid $=1488801031534$ \&index $=6$. Accessed March 6, 2017.

14. Institut national d'études démographiques [French National Institute for Demographical Studies]. Population totale par sexe et âge au 1er janvier 2017, France métropolitaine. 2017. https://www.ined.fr/fichier/ s_rubrique/154/pop.totale.france.metro.fr.xlsx. Accessed March 6, 2017.

15. Guha-Sapir D, Below R, Hoyois P. EM-DAT: The CRED/OFDA International Disaster Database. Université Catholique de LouvainBrussels-Belgium. 2017. https://www.emdat.be. Accessed December 16, 2016.

16. Integrated Research on Disaster Risk. Peril Classification and Hazard Glossary (IRDR DATA Publication No. 1). 2014. http://www. irdrinternational.org/wp-content/uploads/2014/04/IRDR_DATA-ProjectReport-No.-1.pdf (pages 21 and 22). Accessed March 6, 2017.

17. Vandenbroucke JP, von Elm E, Altman DG, et al. Strengthening the reporting of observational studies in epidemiology (STROBE): explanation and elaboration. PLoS Med. 2007;4(10):e297.

18. Kahle D, Wickham, H. ggmap: spatial visualization with ggplot2. $R J$. 2013;5(1):144-161.

19. Ansart S, Pelat C, Boelle PY, et al. Mortality burden of the 1918-1919 influenza pandemic in Europe. Influenza Other Respir Viruses. 2009;3(3): 99-106.

20. Isodorus Hispalensis. Etymologiae. 1160-1165. http://daten.digitalesammlungen.de/ db/0007/bsb00072196/images/index.html?id=00072 $196 \&$ groesser $=\&$ fip $=193.174 .98 .30 \&$ no $=\&$ seite $=25($ book 1 page 25$)$. Accessed May 7, 2017.

21. Buchholz U, Buda S, Reuss A, et al. [Influenza pandemic deaths in Germany from 1918 to 2009. Estimates based on literature and own calculations]. 
Bundesgesundheitsblatt Gesundheitsforschung Gesundheitsschutz. 2016;59(4): 523-536.

22. Mehta A, Beck M, Elliott $P$, et al. Enzyme replacement therapy with agalsidase alfa in patients with Fabry's disease: an analysis of registry data. Lancet. 2009;374(9706):1986-1996.

23. Muenzer J, Jones SA, Tylki-Szymanska A, et al. Ten years of the Hunter Outcome Survey (HOS): insights, achievements, and lessons learned from a global patient registry. Orphanet J Rare Dis. 2017;12(1):82.

24. Mechler K, Mountford WK, Hoffmann GF, Ries M. Ultra-orphan diseases: a quantitative analysis of the natural history of molybdenum cofactor deficiency. Genet Med. 2015;17(12):965-970.

25. Zielonka M, Garbade SF, Kolker S, et al. Quantitative clinical characteristics of 53 patients with MPS VII: a cross-sectional analysis. Genet Med. 2017;19(9):983-988.

26. Basu R. High ambient temperature and mortality: a review of epidemiologic studies from 2001 to 2008. Environ Health. 2009;8:40.

27. CDC. Warning signs and symptoms of heat-related illness. 2011. https:// www.cdc.gov/extremeheat/warning.html. Accessed May 6, 2017.

28. Trickey D, Siddaway AP, Meiser-Stedman R, et al. A meta-analysis of risk factors for post-traumatic stress disorder in children and adolescents. Clin Psychol Rev. 2012;32(2):122-138.

29. Kilic EZ, Ozguven HD, Sayil I. The psychological effects of parental mental health on children experiencing disaster: the experience of Bolu earthquake in Turkey. Fam Process. 2003;42(4):485-495.

30. Ying LH, Wu XC, Lin CD, Chen C. Prevalence and predictors of posttraumatic stress disorder and depressive symptoms among child survivors 1 year following the Wenchuan earthquake in China. Eur Child Adolesc Psychiatry. 2013;22(9):567-575.

31. Green BL, Grace MC, Vary MG, et al. Children of disaster in the second decade: a 17-year follow-up of Buffalo Creek survivors. J Am Acad Child Adolesc Psychiatry. 1994;33(1):71-79.

32. Arbour M, Murray KA, Yoshikawa H, et al. Emotional, physical, and social needs among 0-5-year-old children displaced by the 2010 Chilean earthquake: associated characteristics and exposures. Disasters. 2017;41(2): 365-387.

33. Havenaar JM, Bromet EJ, Gluzman S. The 30-year mental health legacy of the Chernobyl disaster. World Psychiatry. 2016;15(2):181-182.

34. Lengua LJ, Long AC, Smith KI, Meltzoff AN. Pre-attack symptomatology and temperament as predictors of children's responses to the September 11 terrorist attacks. J Child Psychol Psychiatry. 2005;46(6):631-645.

35. Hjemdal O, Vogel PA, Solem S, et al. The relationship between resilience and levels of anxiety, depression, and obsessive-compulsive symptoms in adolescents. Clin Psychol Psychother. 2011;18(4):314-321.

36. Kohrt BA, Worthman CM, Adhikari RP, et al. Psychological resilience and the gene regulatory impact of posttraumatic stress in Nepali child soldiers. Proc Natl Acad Sci U S A. 2016;113(29):8156-8161.

37. Mouchenik Y, Dauriac-Le Masson V, Marquer C, et al. [Trauma and resilience among children 3 to 6 years old in three neighborhoods of Port-au-Prince after the 2010 earthquake in Haiti]. L'Encephale. 2017;43(1):27-31.

38. Halevi G, Djalovski A, Vengrober A, Feldman R. Risk and resilience trajectories in war-exposed children across the first decade of life. J Child Psychol Psychiatry. 2016;57(10):1183-1193.

39. Fayyad J, Cordahi-Tabet C, Yeretzian J, et al. Resilience-promoting factors in war-exposed adolescents: an epidemiologic study. Eur Child Adolesc Psychiatry. 2017;26(2):191-200.

40. BBK. Max und Flocke Helferland. 2011. https://www.max-und-flockehelferland.de/DE/Home/home_node.html. Accessed May 8, 2017.

41. Rothstein DH. Pediatric care in disasters. Pediatrics. 2013;132(4):602-605.

42. Welling DR, Ryan JM, Burris DG, Rich NM. Seven sins of humanitarian medicine. World J Surg. 2010;34(3):466-470.

43. The Lancet. Migrant and refugee children need our actions now. Lancet. 2016;388(10050):1130.
44. Auerbach PS, Norris RL, Menon AS, et al. Civil-military collaboration in the initial medical response to the earthquake in Haiti. N Engl J Med. 2010;362(10):e32.

45. Kearns GL, Abdel-Rahman SM, Alander SW, et al. Developmental pharmacology- drug disposition, action, and therapy in infants and children. N Engl J Med. 2003;349(12):1157-1167.

46. Markenson D, Reynolds S. American Academy of Pediatrics Committee on Pediatric Emergency M, Task Force on T. The pediatrician and disaster preparedness. Pediatrics. 2006;117(2):e340-362.

47. Ishii M, Nagata T. The Japan Medical Association's disaster preparedness: lessons from the Great East Japan earthquake and tsunami. Disaster Med Public Health Prep. 2013;7(5):507-512.

48. Kozu S, Homma H. Lessons learned from the Great East Japan earthquake: the need for disaster preparedness in the area of disaster mental health for children. J Emerg Manag. 2014;12(6):431-439.

49. Disaster Preparedness Advisory Council. Medical countermeasures for children in public health emergencies, disasters, or terrorism. Pediatrics. 2016;137(2):e20154273.

50. Gnauck KA, Nufer KE, LaValley JM, et al. Do pediatric and adult disaster victims differ? A descriptive analysis of clinical encounters from four natural disaster DMAT deployments. Prehosp Disaster Med. 2007;22(1):67-73.

51. Weiner DL, Manzi SF, Waltzman ML, et al. FEMA's organized response with a pediatric subspecialty team: the National Disaster Medical System response: a pediatric perspective. Pediatrics. 2006;117(5 Pt 3):S405-411.

52. Trudeau MO, Rothstein DH. Injuries and surgical needs of children in conflict and disaster: from Boston to Haiti and beyond. Semin Pediatr Surg. 2016;25(1):23-31.

53. Ishiguro A, Togita $\mathrm{Y}$, Inoue $\mathrm{M}$, et al. Identification of disaster-vulnerable communities by use of census data prior to the Great East Japan earthquake. Disaster Med Public Health Prep. 2015;9(1):19-28.

54. Yonekura $\mathrm{T}$, Ueno $\mathrm{S}$, Iwanaka $\mathrm{T}$. Care of children in a natural disaster: lessons learned from the Great East Japan earthquake and tsunami. Pediatr Surg Int. 2013;29(10):1047-1051.

55. Lucchini RG, Hashim D, Acquilla S, et al. A comparative assessment of major international disasters: the need for exposure assessment, systematic emergency preparedness, and lifetime health care. BMC Public Health. 2017;17(1):46.

56. Starmer AJ, Duby JC, Slaw KM, etal., Members of Vision of Pediatrics Task F. Pediatrics in the year 2020 and beyond: preparing for plausible futures. Pediatrics. 2010;126(5):971-981.

57. Khorram-Manesh A. Youth are our future assets in emergency and disaster management. Bull Emerg Trauma. 2017;5(1):1-3.

58. Khorram-Manesh A, Lupesco O, Friedl T, et al. Education in disaster management: what do we offer and what do we need? Proposing a new global program. Disaster Med Public Health Prep. 2016;10(6):854-873.

59. Subbarao I, Lyznicki JM, Hsu EB, et al. A consensus-based educational framework and competency set for the discipline of disaster medicine and public health preparedness. Disaster Med Public Health Prep. 2008;2(1):57-68.

60. Dunlop AL, Logue KM, Vaidyanathan L, Isakov AP. Facilitators and barriers for effective academic-community collaboration for disaster preparedness and response. J Public Health Manag Pract. 2016;22(3):E20-28.

61. Forum on Medical and Public Health Preparedness for Catastrophic Events; Board on Health Sciences Policy; Institute of Medicine. Preparedness, response, and recovery considerations for children and families: workshop summary. 2014. https://www.ncbi.nlm.nih.gov/books/ NBK174835/. Accessed May 3, 2017.

62. Siegel D, Strauss-Riggs K, Costello A. Pediatric disaster preparedness curriculum development- conference report. 2011. https://ncdmph.usuhs. edu/Documents/PedsConferenceReport_1.pdf. Accessed May 3, 2017.

63. Siegel D, Strauss-Riggs K, Needle S. Prioritization of pediatric CBRNE disaster preparedness education and training needs. Clin Pediatr Emerg Med. 2014;15(4):309-317. 